\title{
Long-term outcome of full tendon vertical rectus transposition with Foster suture in unilateral complete sixth cranial nerve palsy
}

This article was published in the following Dove Medical Press journal:

Clinical Ophthalmology

\author{
Worawalun \\ Honglertnapakul ${ }^{1,2}$ \\ Sirinuch Sawanwattanakul ${ }^{1,2}$ \\ Parnchat Pukrushpan ${ }^{1,2}$ \\ Pokpong \\ Praneeprachachon ${ }^{1-3}$ \\ Supharat Jariyakosol ${ }^{1,2}$ \\ 'Department of Ophthalmology, \\ Faculty of Medicine, Chulalongkorn \\ University, Bangkok, Thailand; \\ ${ }^{2}$ Ophthalmology Department, King \\ Chulalongkorn Memorial Hospital, \\ the Thai Red Cross Society, Bangkok, \\ Thailand; ${ }^{3}$ Rutnin Eye Hospital, \\ Bangkok, Thailand
}

Purpose: To evaluate the success rate and long-term motor and sensory outcomes of the full tendon vertical rectus transposition (VRT) with Foster suture for unilateral complete sixth cranial nerve palsy.

Patients and methods: We reviewed the medical records of patients with unilateral acquired sixth cranial nerve palsy who underwent unilateral full tendon VRT with Foster suture between 2005 and 2016 and had a follow-up of $\geq 2$ years. Data on pre- and postoperative diplopia, face turn, ocular deviation, and limitation of abduction were collected. A successful outcome was defined as a horizontal deviation $\leq 10$ prism diopter (PD) of ortho in a primary position at distance and absence of diplopia.

Results: A total of 20 patients were included in this study. Median (IQR) preoperative deviation was esotropia 65 (40-130) PD, which improved to 10 (-4 to 45) PD postoperatively. Median (IQR) improvement of esotropia was $54(30-76)$ PD $(P<0.001)$. Median (IQR) preoperative limitation of abduction was $-15^{\circ}\left(-22.5^{\circ}\right.$ to $10^{\circ}$; negative value means before reaching midline), which improved to $15^{\circ}\left(7.5^{\circ}-45^{\circ}\right)$ pass midline postoperatively. Median (IQR) improvement of abduction deficit was $26^{\circ}\left(15^{\circ}-35^{\circ}\right)(P<0.001)$. Successful surgical outcomes were obtained in eleven patients $(55 \%)$. All patients in the non-successful group $(n=9,45 \%)$ had residual esotropia. Two of them underwent additional bilateral medial rectus recession. No postoperative vertical deviation or torsional diplopia was observed.

Conclusion: In our series, the full tendon VRT with Foster suture in unilateral complete sixth cranial nerve palsy resulted in significant improvement of the ocular alignment and range of abduction over the 2-year follow-up period.

Keywords: sixth cranial nerve palsy, full tendon vertical rectus transposition, Foster suture, posterior fixation suture, lateral fixation suture

\section{Introduction}

Sixth cranial nerve palsy is the most common cause of all ocular nerve palsies. ${ }^{1}$ The etiologies are varied including ischemia, trauma, tumor, increased intracranial pressure, infection, and migraine. Patients with this disease may suffer from palsied lateral rectus muscle, which results in horizontal diplopia worsening in ipsilateral gaze and face turning to the ipsilateral side. Choices of initial management to alleviate a double vision are patching, prism glasses, and botulinum toxin injection. ${ }^{2}$ However, if the symptoms fail to recover and the deviation becomes stable for at least 6 months, surgical intervention is considered. Patients with residual lateral rectus function can be treated with recession and resection surgery of the horizontal recti. Those with poor or absent lateral rectus function generally require more complex muscle surgery, ${ }^{3-8}$
Correspondence: Supharat Jariyakoso Neuro-ophthalmology Division, Department of Ophthalmology, Faculty of Medicine, Chulalongkorn University, 1873 Rama IV Road, Patumwan, Bangkok 10330, Thailand

Email jsupharat@gmail.com $\mathrm{BY}$
NC for commercial use of this work, please see paragraphs 4.2 and 5 of our Terms (https://www.dovepress.com/terms. php). 
including full tendon vertical rectus transposition (VRT) or partial tendon procedure, first described by Hummelshein. ${ }^{9}$ The augmented modalities to increase the effect of these procedures had been variously documented, such as posterior augmentation suture (Foster suture), ${ }^{6}$ resection of the transposed muscle, ${ }^{10-12}$ and additional recession or botulinum toxin injection to ipsilateral medial rectus muscle. ${ }^{13}$ The advantages of additional augmentation suture introduced by Foster ${ }^{6}$ were the ability to improve abducting force without causing significant adduction limitation and the reduction of the risk of anterior segment ischemia since medial rectus muscle surgery is rarely needed. More recently, full tendon transposition of only either superior rectus or inferior rectus to the lateral rectus with posterior fixation suture, with or without medial rectus recession, has been proposed to treat sixth nerve palsies. ${ }^{14-19}$ Complications following full tendon VRT include residual horizontal deviation, vertical deviation, ocular torsion, and anterior segment ischemia. ${ }^{20}$

Previous studies on the outcome of full tendon VRT without Foster suture for the treatment of complete sixth cranial nerve palsy achieved good primary position alignment and functional outcome. ${ }^{1,3,4}$ At present, the outcome and success rate of full tendon VRT with Foster suture are still varied and there is limited information regarding long-term postoperative follow-up..$^{5,6,19,21-23}$ In this study, we aim to present the surgical outcomes of full tendon VRT with Foster suture and the clinical features of patients with unilateral complete sixth cranial nerve palsy. We included only patients who had $>2$-year follow-up time to see the long-term outcome.

\section{Patients and methods}

This study was performed at the Ophthalmology Department, King Chulalongkorn Memorial Hospital and Rutnin Eye Hospital. The study protocol was approved by the Institutional Review Boards of King Chulalongkorn Memorial Hospital and Rutnin Eye Hospital with an exemption for informed consent for this retrospective chart review. The patients' data were kept confidential as the study was conducted in compliance with the Declaration of Helsinki.

Medical records of adult patients aged 18 years or older, who had chronic (at least 6 months) acquired unilateral complete sixth cranial nerve palsy identified as an esotropic eye with a floating saccade toward central gaze, diminished saccadic velocity, and negative force generation test, and underwent full tendon VRT with Foster suture between 2005 and 2016 with at least 2-year follow-up were included. For the posterior augmentation suture (Foster suture) technique, we used two polyester 5-0 sutures, which were placed at the superior and inferior borders of the lateral rectus muscle in a parallel fashion to the lateral rectus insertion. Both sutures were placed at $7 \mathrm{~mm}$ behind the lateral rectus insertion to fix the lateral rectus muscle to the sclera. All the operations were done by either one of the two surgeons (PPP and PCP) with the same surgical technique.

Epidemiological and clinical data were collected, including age, sex, onset, etiology, clinical presentations (diplopia and face turn), and best-corrected visual acuity. The ocular deviation was measured in prism diopter (PD) at distance $(6 \mathrm{~m})$ and near $(33 \mathrm{~cm})$. The limitation of abduction was recorded in degrees by observing light reflex as in Hirschberg technique. Negative abduction means that the ocular motility was limited before reaching midline. The intraoperative and postoperative complications were recorded. Postoperative clinical data including diplopia, face turn, horizontal deviation, and limitation of abduction were documented for $>2$-year follow-up. A successful outcome was defined as no diplopia and horizontal deviation $\leq 10$ PD of ortho at distance.

The demographics, clinical presentations, ocular deviation, and limitation of abduction were analyzed using the median and IQR for continuous variables and the frequency and percentage for categorical variables. Preoperative and postoperative horizontal deviations and limitation of abduction were compared by Wilcoxon signed-rank test. A $P$-value of 0.05 or less was considered significant. SPSS (Version 21; IBM Corporation, Armonk, NY, USA) was used for all statistical analyses.

\section{Results}

A total of 20 patients were included in this study. Patient characteristics such as sex, age, onset, and etiologies are shown in Table 1. The preoperative and postoperative clinical data are described in Table 2. Diplopia was the

Table I Epidemiological data of patients with chronic sixth cranial nerve palsy $(\mathrm{N}=20)$

\begin{tabular}{l|l}
\hline Patient characteristics & \\
\hline Sex & $13(65)$ \\
$\quad$ Male, $\mathrm{n}(\%)$ & $7(35)$ \\
$\quad$ Female, $\mathrm{n}(\%)$ & $38.5(20-57)$ \\
Age (years), median (IQR) & $24(7-240)$ \\
Onset (months), median (IQR) & \\
Etiologies & $12(60)$ \\
$\quad$ Trauma, n (\%) & $5(25)$ \\
$\quad$ CNS tumor, $\mathrm{n}(\%)$ & $3(15)$ \\
Nasopharyngeal carcinoma, n (\%) &
\end{tabular}

Abbreviation: CNS, central nervous system. 
Table 2 Preoperative and postoperative clinical presentations of patients with unilateral sixth cranial nerve palsy $(\mathrm{N}=20)$

\begin{tabular}{|c|c|c|c|}
\hline Clinical presentations & Preoperative data & Postoperative data & $P$-value \\
\hline \multicolumn{4}{|l|}{ Symptoms } \\
\hline Diplopia, n (\%) & $17(85)$ & $10(50)$ & \\
\hline Face turn, n (\%) & $12(60)$ & $5(25)$ & \\
\hline \multicolumn{4}{|l|}{ Ocular examinations } \\
\hline Deviation ${ }^{\mathrm{a}}(\mathrm{PD})$, median (IQR) & $65(40-130)$ & $10(-4$ to 45$)$ & $<0.00 I^{*}$ \\
\hline Limitation of abduction ${ }^{\mathrm{b}}$ (degrees), median (IQR) & $-15(-22.5$ to 10$)$ & $15(7.5-45)$ & $<0.00 I^{*}$ \\
\hline
\end{tabular}

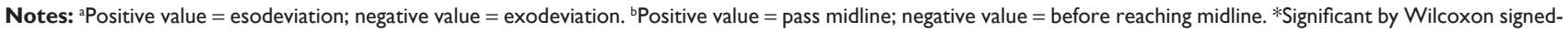
rank test.

Abbreviation: $\mathrm{PD}$, prism diopter.

most frequent clinical presentation $(n=17,85 \%)$, followed by face turn $(\mathrm{n}=12,60 \%)$. After the surgery, diplopia and face turn resolved in 7 (41\%) and 7 (58\%) patients, respectively. The median preoperative deviation was esotropia 65 (IQR, 40-130) PD, which improved to 10 (IQR, -4 to 45) PD postoperatively. The median preoperative limitation of abduction was $-15^{\circ}\left(\mathrm{IQR},-22.5^{\circ}\right.$ to $\left.10^{\circ}\right)$, which improved to $15^{\circ}\left(\mathrm{IQR}, 7.5^{\circ}-45^{\circ}\right)$ postoperatively. The esodeviation and limitation of abduction improved in all patients. The median improvement of esodeviation was 54 (IQR, 30-76) $\mathrm{PD}$ and the median improvement of limitation of abduction was $26^{\circ}\left(\mathrm{IQR}, 15^{\circ}-35^{\circ}\right)$ as shown in Table 2. A long-term successful outcome was obtained in 11 of 20 cases (55\%). In the non-successful group ( $\mathrm{n}=9,45 \%$ ), all cases had residual esotropia and two $(22.2 \%)$ of them underwent additional bilateral medial rectus recession. No other complications, including postoperative vertical deviation, ocular torsion, or anterior segment ischemia, were found.

\section{Discussion}

In this case series, trauma was the most common cause of unilateral complete sixth cranial nerve palsy. The higher frequency of trauma may be related to the fact that we included patients who received full tendon VRT, as complete recovery can occur in many etiologies such as cranial nerve ischemia, post-viral infection, and increased intracranial pressure. In line with previous studies, ${ }^{5,6}$ we found that the most frequent clinical presentation other than esodeviation was diplopia, followed by face turn.

In previous studies, the successful outcomes of full tendon VRT without posterior fixation suture were found to be varied (52\%-80\%) ${ }^{1,3,4}$ To improve the abduction force, lateral fixation suture was introduced by Foster. ${ }^{6}$ He studied the effect of this additional suture in Duane syndrome, sixth cranial nerve palsy, gaze palsy, and recurrent esotropia after transposition procedure. He reported $100 \%$ success rate in four patients with unilateral sixth cranial nerve palsy who received full tendon VRT with Foster suture. Another study conducted by Struck ${ }^{21}$ investigated the effect of this augmented procedure in ten patients: five with Duane syndrome and five with sixth nerve palsy. In the latter group, he reported successful outcomes in four of five patients (80\%). The criteria of successful horizontal alignment were defined as a reduction or an elimination of head turn, a deviation $\leq 10 \mathrm{PD}$, and a resolution of diplopia. He also proposed a modification of the original technique by placement of a single fixation suture to balance vertical vector between transposed superior rectus and inferior rectus, which reduced the incidence of migration, dehiscence, or breakage of fixation stitches and minimized the lateral slippage of the muscle belly that was previously described by Rosenbaum. ${ }^{24}$

In our study, the overall success rate of full tendon VRT with Foster suture was 55\% and all patients had significant improvement of esodeviation and abduction motility for $>24$ months. The reason for our lower success rate and higher rate of residual esotropia compared to previous reports is that the overall preoperative esodeviation in our study was much higher than in other studies. The median of preoperative esodeviation in our series was $65 \mathrm{PD}$, which is the highest compared to other studies (Table 3 ). Another reason is that the follow-up time in our study was longer than others. In our experience, there were a number of patients who loss to follow-up in the long-term period due to favorable surgical outcome. However, our technique of full tendon VRT with Foster suture had the most powerful effect of improvement of esodeviation compared to previous studies (Table 3 ). The detailed data regarding the improvement of esodeviation and limitation of abduction of full tendon VRT with Foster suture, along with the suture type and the location of suture placement from previous studies, are presented in Table 3 .

To date, there have been many articles mentioning the efficacy of several new transposition techniques, such as superior rectus transposition with or without medial rectus recession and inferior rectus transposition with medial rectus 


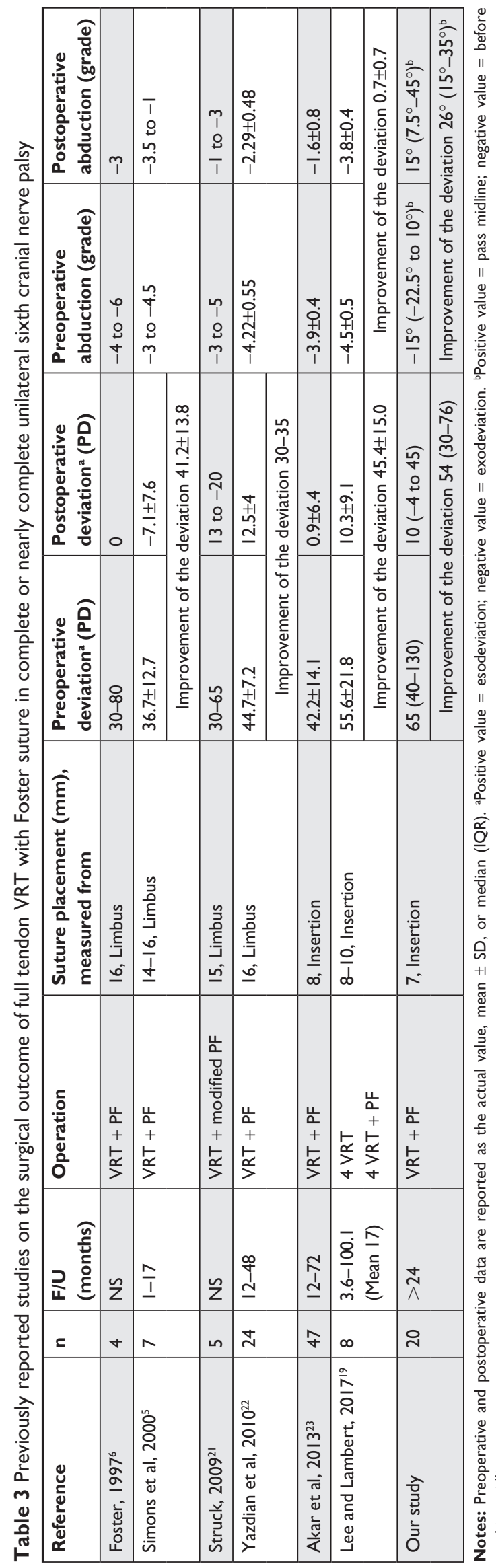

recession. ${ }^{14-18}$ A recent study by Lee and Lambert ${ }^{19}$ found a comparable surgical outcome of full tendon VRT with or without Foster suture and superior rectus transposition with medial rectus recession. Though the surgical outcomes were similar between the two groups, there were fewer additional procedures in the latter group.

To our knowledge, this is the first study to report the outcome of full tendon VRT with Foster suture in the treatment of unilateral complete sixth cranial nerve palsy that included all patients with a follow-up period of $>2$ years. The limitation of our study is the small number of patients. The main reason for this was that some patients were lost to follow-up before 2 years and were not included in our study. Future studies may require a larger number of patients and longer follow-up time.

\section{Conclusion}

In conclusion, full tendon VRT with Foster suture in unilateral complete sixth cranial nerve palsy provided good alignment and improved abducting motility for over 2-year follow-up period with the median improvement of esodeviation of $54 \mathrm{PD}$ and limitation of abduction of $26^{\circ}$.

\section{Acknowledgment}

This study was supported by Ratchadapiseksompotch Fund, Faculty of Medicine, Chulalongkorn University (Grant no RA 55/35).

\section{Disclosure}

The authors report no conflicts of interest in this work.

\section{References}

1. Yurdakul NS, Ugurlu S, Maden A. Surgical management of chronic complete sixth nerve palsy. Ophthalmic Surg Lasers Imaging. 2011; 42(1):72-77.

2. Holmes JM, Leske DA, Christiansen SP. Initial treatment outcomes in chronic sixth nerve palsy. J AAPOS. 2001;5(6):370-376.

3. Bansal S, Khan J, Marsh IB. Unaugmented vertical muscle transposition surgery for chronic sixth nerve paralysis. Strabismus. 2006;14(4): $177-181$

4. Holmes JM, Leske DA. Long-term outcomes after surgical management of chronic sixth nerve palsy. J AAPOS. 2002;6(5):283-288.

5. Simons BD, Siatkowski RM, Neff AG. Posterior fixation suture augmentation of full-tendon vertical rectus muscle transposition for abducens palsy. J Neuroophthalmol. 2000;20(2):119-122.

6. Foster RS. Vertical muscle transposition augmented with lateral fixation. J AAPOS. 1997;1(1):20-30.

7. Britt MT, Velez FG, Thacker N, Alcorn D, Foster RS, Rosenbaum AL. Partial rectus muscle-augmented transpositions in abduction deficiency. J AAPOS. 2003;7(5):325-332.

8. Gunton KB. Vertical rectus transpositions in sixth nerve palsies. Curr Opin Ophthalmol. 2015;26(5):366-370.

9. Hummelshein E. Uber Schnentransplantation am Ague. Ophthal Gesselschft. 1907;34:248-253. 
10. Brooks SE, Olitsky SE, deB Ribeiro G. Augmented Hummelsheim procedure for paralytic strabismus. J Pediatr Ophthalmol Strabismus. 2000;37(4):189-195, quiz 226-187.

11. Couser NL, Lenhart PD, Hutchinson AK. Augmented Hummelsheim procedure to treat complete abducens nerve palsy. J AAPOS. 2012; 16(4):331-335.

12. Hendler K, Pineles SL, Demer JL, Yang D, Velez FG. Adjustable augmented rectus muscle transposition surgery with or without ciliary vessel sparing for abduction deficiencies. Strabismus. 2014; 22(2):74-80.

13. Flanders M, Qahtani F, Gans M, Beneish R. Vertical rectus muscle transposition and botulinum toxin for complete sixth nerve palsy. Can J Ophthalmol. 2001;36(1):18-25.

14. Mehendale RA, Dagi LR, Wu C, Ledoux D, Johnston S, Hunter DG. Superior rectus transposition and medial rectus recession for Duane syndrome and sixth nerve palsy. Arch Ophthalmol. 2012;130(2):195-201.

15. Velez FG, Oltra E, Isenberg SJ, Pineles SL. Assessment of torsion after superior rectus transposition with or without medial rectus recession for Duane syndrome and abducens nerve palsy. J AAPOS. 2014;18(5): $457-460$

16. Patil-Chhablani P, Kothamasu K, Kekunnaya R, Sachdeva V, Warkad V. Augmented superior rectus transposition with medial rectus recession in patients with abducens nerve palsy. J AAPOS. 2016;20(6):496-500.
17. Agarwal R, Sharma M, Saxena R, Sharma P. Surgical outcome of superior rectus transposition in esotropic Duane syndrome and abducens nerve palsy. J AAPOS. 2017;22(1):12-16.e1.

18. Velez FG, Chang MY, Pineles SL. Inferior rectus transposition: a novel procedure for abducens palsy. Am J Ophthalmol. 2017;177:126-130.

19. Lee Y-H, Lambert SR. Outcomes after superior rectus transposition and medial rectus recession versus vertical recti transposition for sixth nerve palsy. Am J Ophthalmol. 2017;177:100-105.

20. Simon JW, Grajny A. Anterior segment ischemia following augmented 2-muscle transposition surgery. J AAPOS. 2004;8(6):586-587.

21. Struck MC. Augmented vertical rectus transposition surgery with single posterior fixation suture: modification of Foster technique. J AAPOS. 2009;13(4):343-349.

22. Yazdian Z, Rajabi MT, Ali Yazdian M, Rajabi MB, Akbari MR. Vertical rectus muscle transposition for correcting abduction deficiency in Duane's syndrome type 1 and sixth nerve palsy. J Pediatr Ophthalmol Strabismus. 2010;47(2):96-100.

23. Akar S, Gokyigit B, Pekel G, Demircan A, Demirok A. Vertical muscle transposition augmented with lateral fixation (Foster) suture for Duane syndrome and sixth nerve palsy. Eye. 2013;27(10):1188-1195.

24. Rosenbaum AL. Costenbader Lecture. The efficacy of rectus muscle transposition surgery in esotropic Duane syndrome and VI nerve palsy. $J$ AAPOS. 2004;8(5):409-419.
Clinical Ophthalmology

\section{Publish your work in this journal}

Clinical Ophthalmology is an international, peer-reviewed journa covering all subspecialties within ophthalmology. Key topics include: Optometry; Visual science; Pharmacology and drug therapy in eye diseases; Basic Sciences; Primary and Secondary eye care; Patient Safety and Quality of Care Improvements. This journal is indexed on

Submit your manuscript here: http://www.dovepress.com/clinical-ophthalmology-journal

\section{Dovepress}

PubMed Central and CAS, and is the official journal of The Society of Clinical Ophthalmology (SCO). The manuscript management system is completely online and includes a very quick and fair peer-review system, which is all easy to use. Visit http://www.dovepress.com/ testimonials.php to read real quotes from published authors. 